TM-1619

[SSC-N-662]

\title{
A Blanket Design, Apparatus, and Fabrication Techniques for the Mass Production of Multilayer Insulation Blankets for the Superconducting Super Collider*
}

\author{
J. D. Gonczy, W. N. Boroski, R. C. Niemann, J. G. Otavka, M. K. Ruschman, and C. J. Schoo \\ Fermi National Accelerator Laboratory \\ P.O. Box 500, Batavia, Illinois 60510
}

September 1989

* Presented at the Cryogenic Engineering Conference, Los Angeles, California, July 24-28, 1989; submitted to Adv. Cryo. Eng. 
A BLANKET DESIGN, APPARATUS, AND FABRICATION TECHNIQUES FOR THE MASS PRODUCTION OF MULTILAYER INSULATION BLANKETS FOR THE SUPERCONDUCTING SUPER COLLIDER

J.D. Gonczy, W.N. Boroski, R.C. Niemann, J.G. Otavka, M.K. Ruschman, and C.J. Schoo

Fermi National Accelerator Laboratory

Batavia, Illinois

\section{ABSTRACT}

The multilayer insulation (MLI) system for the Superconducting Super Collider (SSC) consists of full cryostat length assemblies of aluminized polyester film fabricated in the form of blankets and installed as blankets to the $4.5 \mathrm{~K}$ cold mass and the $20 \mathrm{~K}$ and $80 \mathrm{~K}$ thermal radiation shields. Approximately 40,000 MLI blankets will be required in the 10,000 cryogenic devices comprising the SSC accelerator. Each blanket is nearly 17 meters long and 1.8 meters wide. This paper reports the blanket design, an apparatus, and the fabrication method used to mass produce pre-fabricated MLI blankets. Incorporated in the blanket design are techniques which automate quality control during installation of the MLI blankets in the SSC cryostat. The apparatus and blanket fabrication method insure consistency in the mass produced blankets by providing positive control of the dimensional parameters which contribute to the thermal performance of the MLI blanket. By virtue of the fabrication process, the MLI blankets have inherent features of dimensional stability, three-dimensional uniformity, controlled layer density, layer-to-layer registration, interlayer cleanliness, and interlayer material to accommodate thermal contraction differences.

\section{INTRODUCTION}

Laboratory measurements describing the thermal performance of candidate MLI systems are an important first consideration when selecting the MLI systems for the SSC.1,2 Equal in importance with laboratory measurements are concerns regarding the installation of the MLI system in the SSC cryostat. During cryostat operation, these concerns are generally recognized as differences between the calculated heat load of the cryostat (based on laboratory measurements) and the actual heat 'load that is measured in the field. At the root of these differences is the relative inability to duplicate in a practical manner at installation the same MLI geometry and boundary conditions as was tested in the laboratory. Since the ultimate operating cost of the SSC will depend principally on the ability to prevent heat inleak to the cryogens, it is essential during the installation of the SSC MLI system that the MLI geometry which was measured in the laboratory is, in fact, duplicated 40,000 times in the 10,000 SSC cryogenic devices. 
Apart from the laboratory measurements, the challenges to developing a practical MLI system for the SSC which is both predictable and consistent in thermal performance are: 1) the design of an MLI system that lends itself to mass fabrication and to mass installation techniques which eliminate decision making during installation of the MLI blanket in the SSC cryostat; 2) the development of an apparatus to implement the blanket design in a cost effective manner; and, 3) the development of a fabrication method that uses ordinary production skills. These challenges have been accomplished and are described herein.

\section{OVERVIEW - DESIGN GOALS FOR THE SSC MLI SYSTEM}

The objective of the MLI system is to limit cryostat heat load from thermal radiation and residual gas conduction to the low levels specified by the SSC design requirements. ${ }^{3}$ The MLI system must maintain these low heat load levels during the 20 plus years lifetime of the accelerator while in an environment of nuclear radiation and for extended periods of operational upset conditions including thermal cycles and poor insulating vacuum. Essential to the SSC accelerator is a blanket design which passively addresses transient conditions by providing high layer density MLI for gas conduction shielding and has sufficient volumetric heat capacity to dampen transient effects. ${ }^{4}$

Within each accelerator half-cell, the MLI systems of six dipole magnets, one quadrupole magnet, one spool piece, and the associated magnet interconnection regions share a common insulating vacuum. The insulating vacuum in each 114 meter long half-cell must be capable of maintaining a pressure of $1 \times 10^{-6}$ Torr that has been established by cryopumping from a rough vacuum isolated near $10^{-2}$ Torr. At $1 \times 10^{-6}$ Torr, the design requirements limit the combined heat load from infrared and gas conduction at $638 \mathrm{~mW} / \mathrm{M}^{2}$ to $80 \mathrm{~K}, 87 \mathrm{~mW} / \mathrm{M}^{2}$ to $20 \mathrm{~K}$, and $3.3 \mathrm{~mW} / \mathrm{M}^{2}$ to $4.5 \mathrm{~K}$.

Ionizing radiation levels discharged radially along the accelerator are anticipated to vary with the local cryostat geometry. For example within the cryostat cold mass, the collars clamping the magnet coils and the iron yoke afford some shielding for the MLI from the ionizing radiation. In non shielded regions such as at the magnet interconnections, higher radiation levels are expected. Over the lifetime of the accelerator, the total radiation absorbed dose in shielded areas is expected to remain below $1.2 \times 10^{5}$ rad. At the magnet interconnections, the absorbed dose is not expected to exceed $5 \times 10^{8} \mathrm{rad}$.

\section{SSC MLI BLANKET DESIGN}

Material Considerations - Table 1 lists the materials used in the SSC blanket design. Polyester materials (in particular polyethylene tercphthalate) were selected as the overall best choice for each of the MLI blanket components. The materials selection and blanket geometry were formulated after careful consideration of a number of published works reporfing on MLI material properties; including mechanical strengths, nuclear irradiation dosages, irradiated gas evolution, hygroscopicity, vacuum outgassing rates, interstitial gas pressures, and crack geometries and thermal performance measurements. s.11 $^{\text {p }}$ 
Table 1. SSC MLI blanket materials

\begin{tabular}{|c|c|c|c|}
\hline $\begin{array}{c}\text { GLANKET } \\
\text { COMPONENT }\end{array}$ & MATERIAL & DESCRIPTION & COMPANY \\
\hline REFLECTOR & $\begin{array}{l}\text { ALUMINUM } \\
\text { VC:A } \\
\text { VACCUMM } \\
\text { OEPOSITION }\end{array}$ & 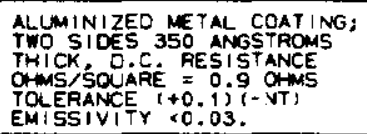 & $\begin{array}{l}\text { MULTIPLE } \\
\text { VENDORS }\end{array}$ \\
\hline REFLECTOR SUESTRATE & $\begin{array}{l}\text { PQL YETHYLENE } \\
\text { TEREPHTHALATE }\end{array}$ & $\begin{array}{l}\text { FLAT FILM } 25 \text { HM THICK, } \\
\text { NO PERFOAMTIONS }\end{array}$ & DUPONT \& CO. \\
\hline SPACER & $\begin{array}{l}\text { POLYETHYLENE } \\
\text { TEREPHTHALATE }\end{array}$ & $\begin{array}{l}\text { SPUNBONOED POYYESTER, } \\
\text { O. I mm THICK, I }\end{array}$ & REEMAY, INC. \\
\hline COVER LAYERS & $\begin{array}{l}\text { POLYETHYLENE } \\
\text { TEREPHTHALATE }\end{array}$ & $\begin{array}{l}\text { SPUNBONOED PQYYESTER, } \\
\text { O.23mm THICK, } 46 \mathrm{~g} / \mathrm{M}^{\prime}\end{array}$ & REEMAY, INC. \\
\hline HOOK FASTENER & POLYESTER & HOOK 190, WHITE & VELCRO USA, INC. \\
\hline LOOP FASTENER & POLYESTER & $\begin{array}{l}\text { LOOP } 2000, \text { WHITE } \\
\text { WOTH: } 25 \mathrm{~mm}\end{array}$ & VELCFO USA, INC. \\
\hline THREAD & POL YESTER & V125WHITE & $\begin{array}{l}\text { GELDING CORTI ICELL I } \\
\text { THREAD CO. }\end{array}$ \\
\hline
\end{tabular}

Blanket Design Geometry - The design geometry for the outer 80K MLI blanket is shown in Fig. 1 and illustrates physical dimensions and blanket components typical of the MLI covering the SSC thermal shields. The blanket design incorporates 32-reflective layers of double aluminized polyethylene terephthalate (PET) film each separated by a single thin spacer layer of spunbonded PET material. A thicker layer of spunbonded PET material covers the blanket top and bottom, and positions polyester hook and loop fasteners at the blanket edges. The fasteners are affixed to the cover layers by sewing. A thicker PET layer is also located midway in the blanket and separates the upper and lower 16 reflective layers of MLI. The multiple blanket layers are sewn together as an assembly along both edges of the blanket. Polyester thread is used in all sewing processes. At each blanket edge, the upper cover and MLI layers are sewn together through to the midlayer with the thread terminated in the thicker midlayer. The seam location is incremented laterally along the midlayer where the lower MLI layers are sewn through to the lower cover layer. The resulting step in the sewn seam attempts to reduce heat conduction through the blanket by interrupting and lengthening the solid conduction path of the thread.

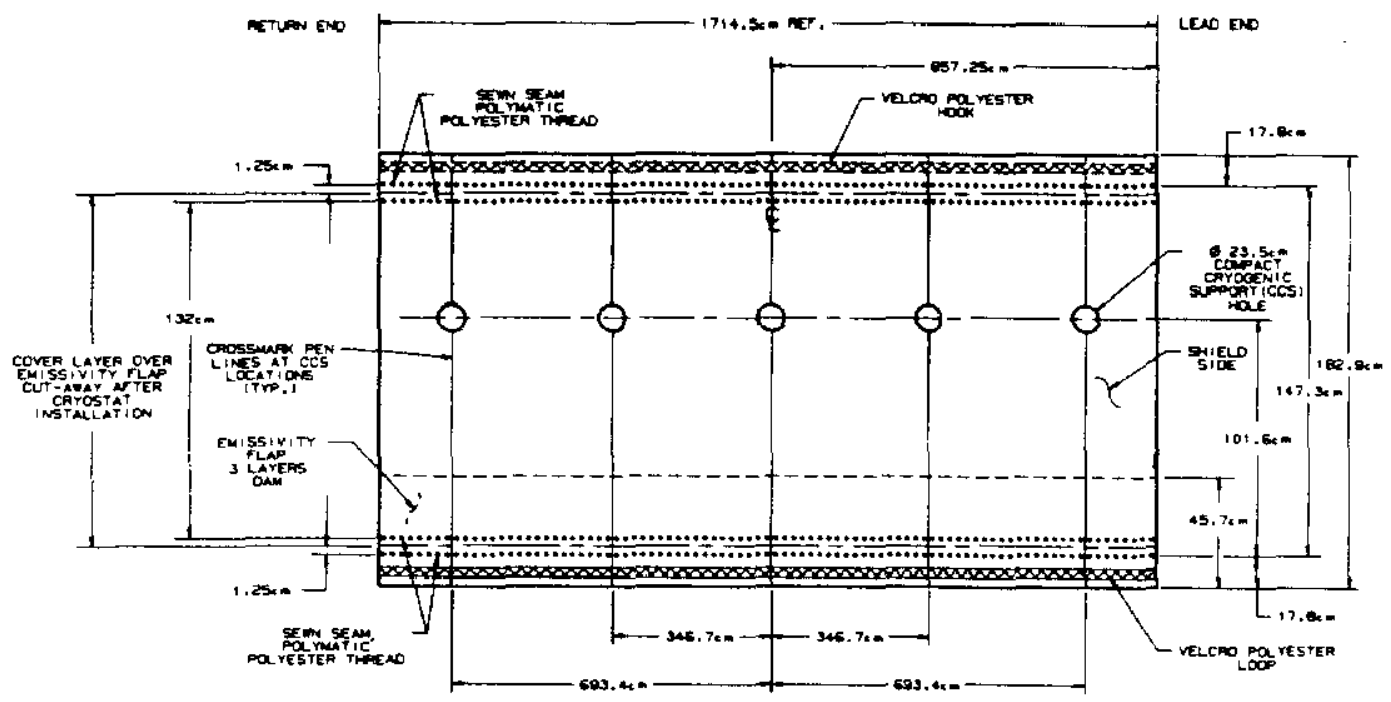

Fig. 1. SSC dipole cryostat $80 \mathrm{~K}$ outer blanket design 
Dimensional Parameters Considered in the Blanket Design - Each MLI blanket for the SSC is fitted with openings through which the support system for the cold mass and shield assemblies protrude. These holes also serve as evacuation ports which access the interstitial spaces between the many blanket layers. Interlayer registration of the holes through the MLI blanket must be maintained during the logistics of fabrication, handling, and installation of the 17 meter long by 1.8 meter wide blankets. Also critical to the thermal performance of the MLI system is a uniform MLI layer density. Uniform layer density using previous MLI fabrication techniques has been extremely difficult to maintain at installation. Proper alignment of the blanket layers in the length and width dimensions and control of MLI layer density is assured by sewing together the multiple layers of the blanket along each blanket edge for the entire length of the blanket.

During the operation of the SSC, the MLI blankets are subjected to extreme temperature gradients along their thicknesses causing the layers nearest the cryogenic structure to experience dimensional contraction to a greater extent than the layers furthest from the cryogenic structure. The SSC blanket fabrication method provides integral material in its length and width dimensions to assist thermal contraction to liquid helium ternperature.

\section{BLANKET WINDING APPARATUS AND FABRICATION METHOD}

Pictured in Fig. 2 is a large diameter winding apparatus used to fabricate the MLI blankets for the $4.5 \mathrm{~K}$ cold mass, and the $20 \mathrm{~K}$ and $80 \mathrm{~K}$ shields. The apparatus consists of a rotatable mandrel having a 5.5 meter fixed diameter and an outer surface that is crowned with a convex crosssection. Accessory supply spools hold the blanket reflective and spacer materials. The function of the apparatus is to wrap the appropriate number of MLI blanket layers around the mandrel. Since each wrap of MLI material increases the circumference of the mandrel, each successive layer of material is slightly greater in length than the preceding layer.

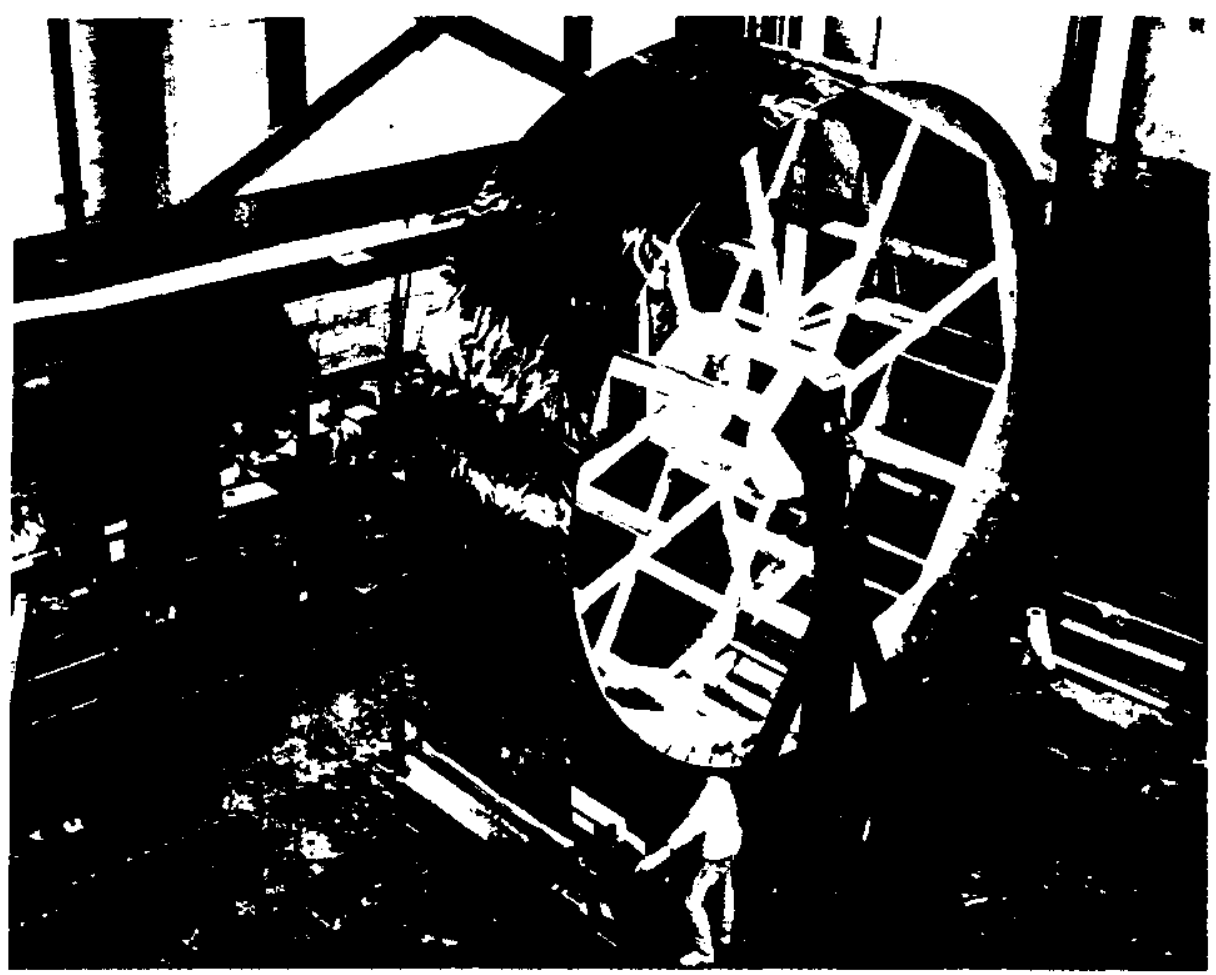

Fig. 2. Large diameter winding apparatus for MLI blanket production 
Likewise in the transverse direction across the crowned surface, each successive layer is wound on the circumference on an increasing crown. The finished blanket is then bound together at its edges by rotating the blanket through a stationary sewing machine. A single cut is made directly across the width of the MLI, and the blanket is removed from the mandrel. The resulting MLI blanket has sufficient length and width for an SSC shield assembly. In addition, there is locked between the parallel sewn seams: dimensional stability, three-dimensional uniformity, controlled layer density, interlayer registration, interlayer cleanliness, and extra material in successive layers in the length and width directions to aid thermal contraction, since, the last layer wrapped on the mandrel is designated for installation as the first layer installed against the cold surface. Fig. 3 shows the procedural steps used to fabricate the outer MLI blanket of the $80 \mathrm{~K}$ thermal shield. The blanket cover layers are illustrated in Fig. 4.

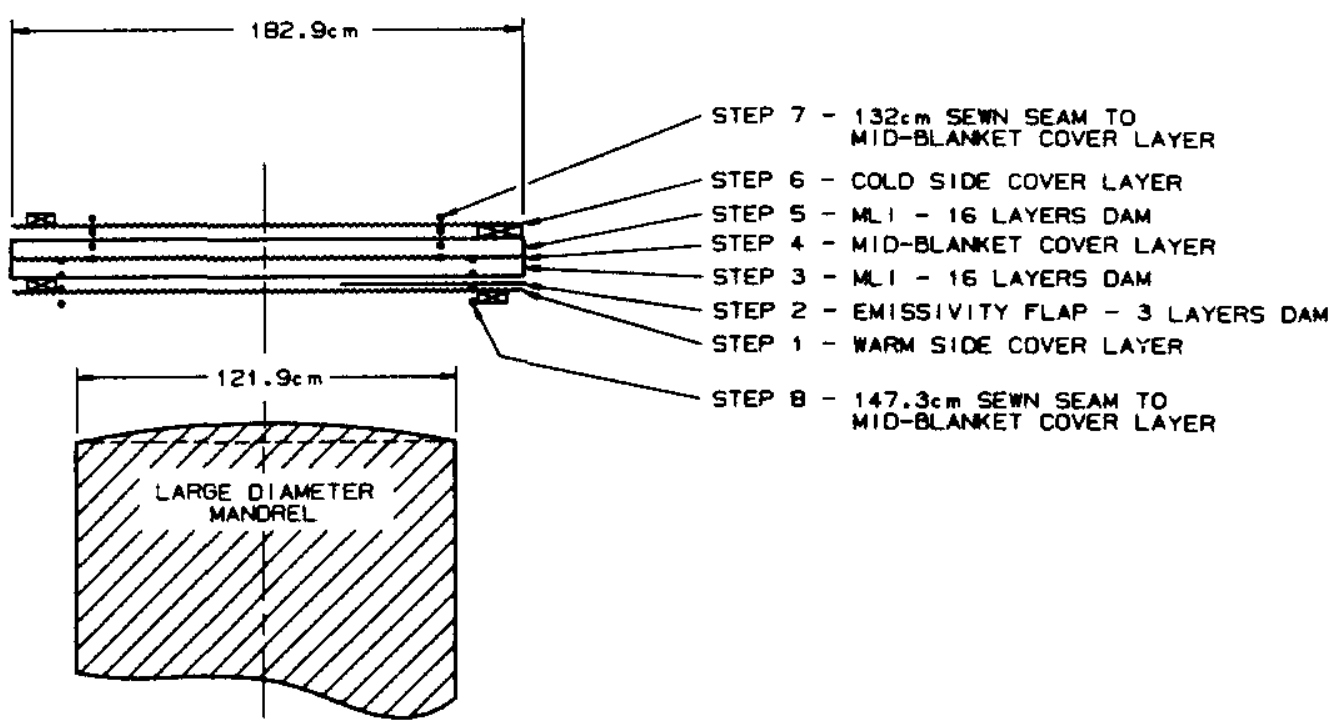

Fig. 3. MLI blanket fabrication steps

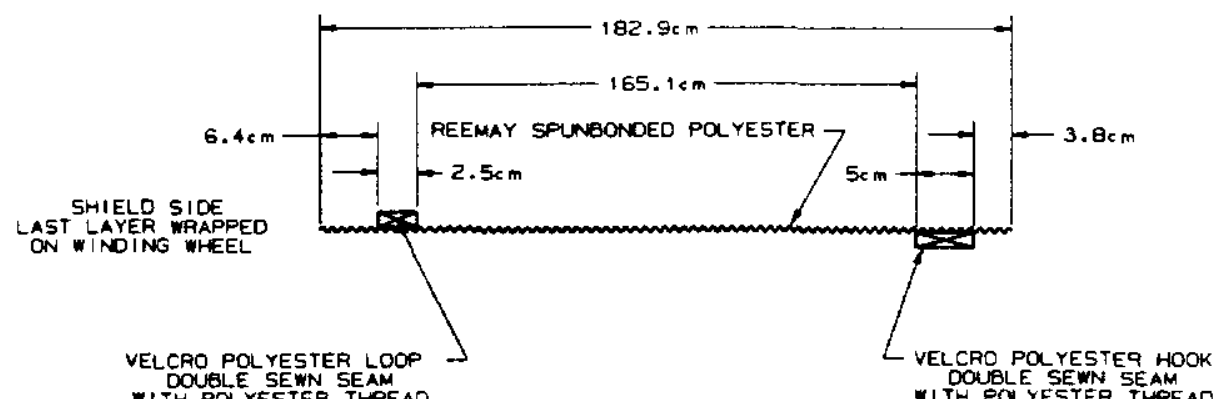
WITH POLYESTEF THPEAD WITH POLYESTER THREAD

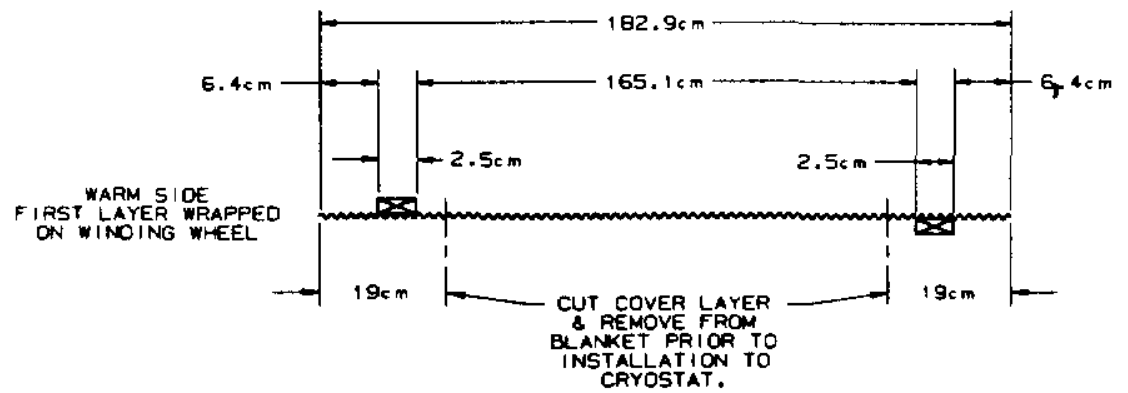

Fig. 4. Cover layers for outer $80 \mathrm{~K}$ MLI blanket 


\section{BLANKET INSTALLATION}

The tightness of the blanket wrap during installation in the SSC cryostat is fixed by the blanket design. Parallel Velcro strips sewn to the blanket cover layers serve to secure the blanket at installation. The Velcro strips are separated by a distance that was determined empirically for each blanket (inner and outer) by trial fitting blanket sections onto actual shields and adjusting the Velcro separation until the desired blanket fit around the shield was obtained. See Fig. 4. Since both edges of the blanket are sewn, the MLI material locked between the sewn seams is caused to wrinkle or wave as the blanket is wrapped around the shield. This wrinkling occurs as a result of the regimented layers being unable to separately slide across each other as would be the case, for example, if only one edge of the blanket were sewn. Because of layer-to-layer registration, these wrinkles or waves usually have a uniform thickness along the wave that is approximately the same thickness as in the main body of the blanket. The MLI layer density is therefore little affected by the wrinkles, which as a favorable element, provide added material for thermal contraction of the blankets.

At installation, the blanket is wrapped around the shield such that the edges of the blanket overlap to form a stepped layer joint. Fig. 5 shows the staggered joint location of the blankets which alternate shield sides for the inner and the outer blankets. As the blanket edges are drawn together, tension on the blanket is taken by the sewn seams and cover layers. The MLI material located in the greater blanket area between the sewn seams is isolated from the tension by the seams. Against the shield surface, opposite edges of the lower cover layer are secured to each other by the full engagement of the Velcro strips. As the lower cover layers are overlapped and secured, crossmark lines penned on the cover layers at the locations of the support hole penetrations are superimposed, thereby confirming a cylindrical blanket assembly between each support. The crossmark alignment procedure is a quality control measure used to assure that sufficient MLI material is stored between supports locations to locally accommodate MLI axial thermal contraction. The MLI layers between the blanket cover layers are then joined along the entire blanket length using a stepped-butted joint geometry. See Fig. 6 . The joint configuration is completed by the full engagement of the upper Velcro strips over the stepped joint. The resulting blanket installation is twice secured from opening by the closure of the two Velcro pairs. An emissivity flap consisting of a few layers of aluminized polyester is folded over the joint area to provide a low emissivity surface to thermal radiation.

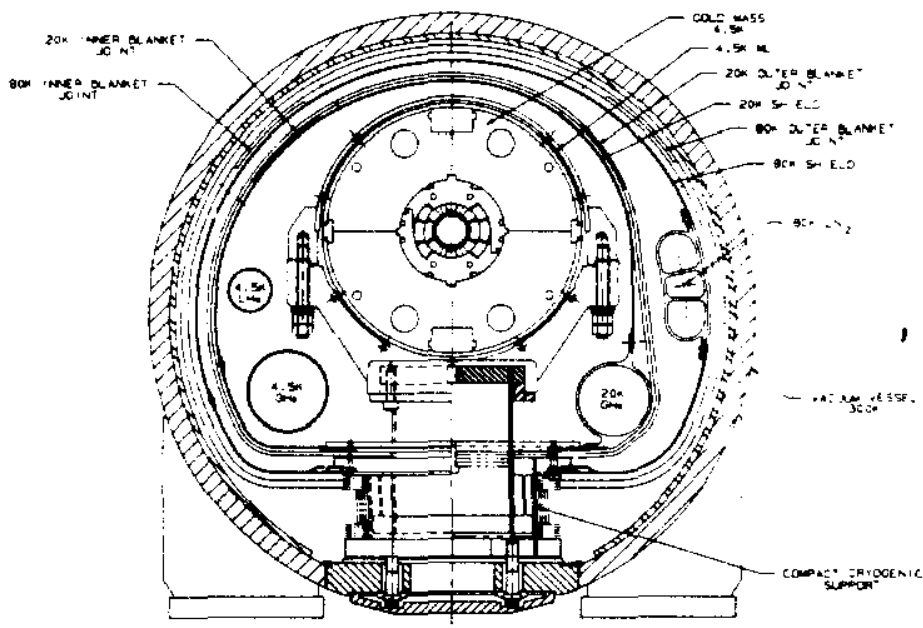

Fig. 5. SSC cryostat cross-section and blanket joint locations 


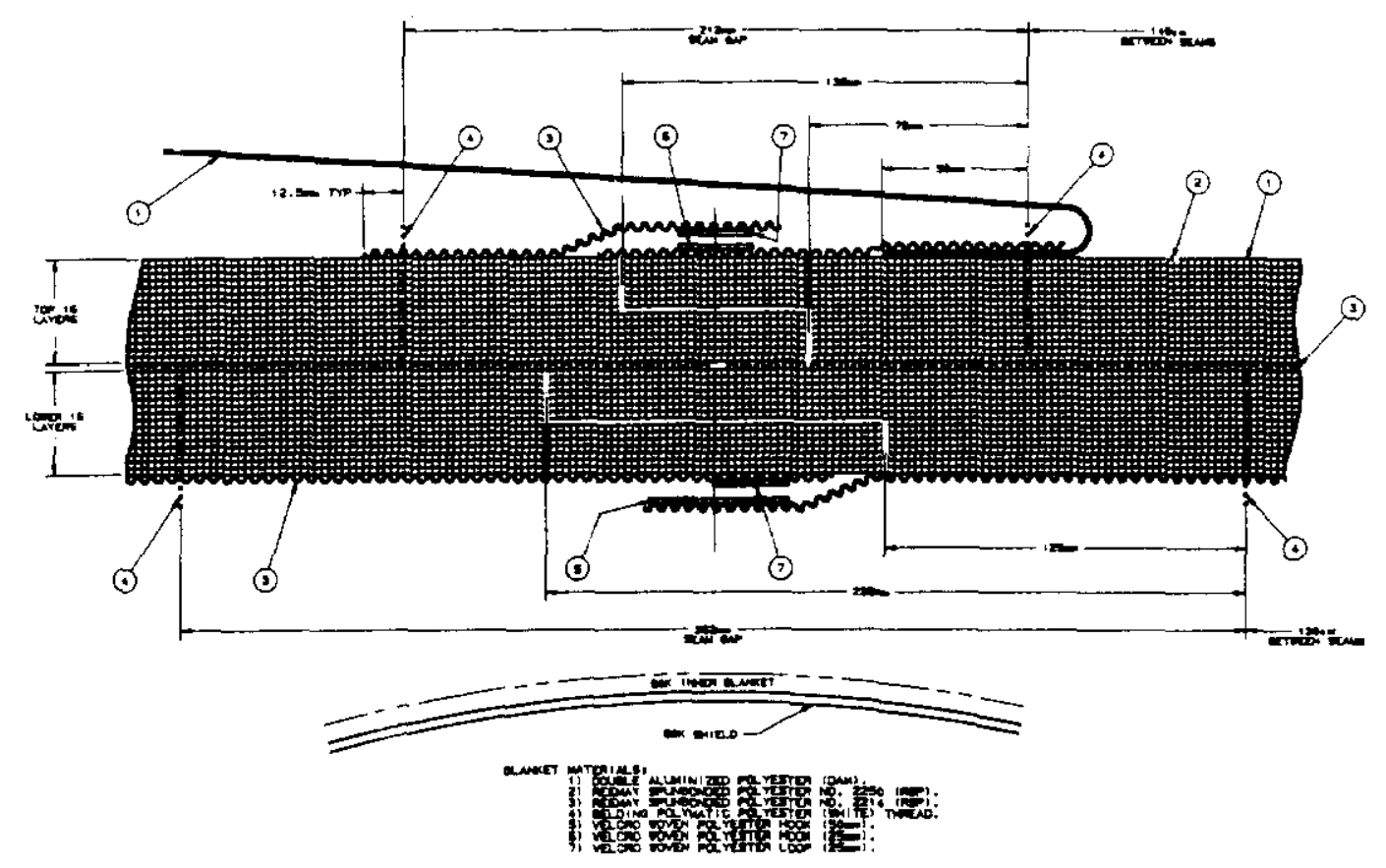

Fig. 6. Blanket joint illustrating stepped-butted MLI seams

\section{CONCLUSIONS}

The apparatus and blanket fabrication method are cost effective means to mass produce dimensionally uniform MLI blankets:

1) few production personnel are needed to fabricate a finished blanket;

2) layer by layer materials handling is eliminated, thereby greatly reducing labor costs and insuring interlayer cleanliness;

3) precise location and insertion of penetrations or holes in the MLI can be done during blanket fabrication while the MLI is on the winding mandrel.

The blanket design allows the MLI at installation to be treated as an ordinary component part in the cryostat assembly.

Quality control measures which use Velcro fasteners and alignment crossmarks are incorporated in the blanket design and predetermine the blanket installation geometry in the SSC cryostat. The Velcro fasteners also eliminate the need for MLI tape (adhesive tape) to secure the blanket, precluding adhesive outgassing and virtual leaks from trapped gases beneath the tape.

By virtue of the blanket design, the apparatus, and the fabrication method, the MLI installation geometry in each of the 10,000 cryostats will be dimensionally uniform.

By providing positive control of the dimensional parameters which contribute to the MLI blanket thermal performance, a consistent operational performance of the MLI system is established in each of the 10,000 SSC cryostats. 


\section{ACKNOWLEDGEMENTS}

The authors express their appreciation to Messrs. C. Niemann for his able assistance developing MLI blanket fabrication techniques, and C. Grimm for his continued support in illustrating this work.

\section{REFERENCES}

1. T. Ohmori, et. al., Thermal performance of candidate SSC magnet thermal insulation systems, in: "Advances in Cryogenic Engineering," Vol. 33, Plenum Press, New York (1988), p. 323

2. J. D. Gonczy, W.N. Boroski, and R.C. Niemann, Thermal performance measurements of a 100 percent polyester MLI system for the superconducting super collider part II: laboratory results $(300 \mathrm{~K}-80 \mathrm{~K})$, presented at the CEC conference, July 24-28, 1989, Los Angeles, CA.

3. SSC Central Design Group, 'Prime item requirements for superconducting super collider prototype and pre-production magnets,' Specification number SSC-MAG-D-1010 (May 15, 1989).

4. C. L. Tien and G.R. Cunnington, Cryogenic insulation heat transfer, in: "Advances in Heat Transfer," Vol. 9, Academic Press, New York (1973), P. 349

5. M. H. Van de Voorde and C. Restat, 'Selection guide to organic materials for nuclear engineering', CERN 72-7 (1972).

6. H. Burmeister, et al., Test of multilayer insulations for use in the superconducting proton-ring of HERA, in: "Advances in Cryogenic Engineering," Vol. 33, Plenum Press, New York (1988), p. 313.

7. A. P. M. Glassford and C.K. Liu, 'Outgassing rate of multilayer insulation materials at ambient temperature', J. Vac. Sci. Technol., Vol. 17, No. 3, May/June 1980, p. 696.

8. J. W. Price, Measuring the gas pressure within a high-performance insulation blanket, in: "Advances in Cryogenic Engineering," Vol. 13, Plenum Press, New York (1967), p. 662.

9. W. Burgess and Ph. Lebrun, 'Compared performance of Kapton and Mylar based Superinsulation, in: "Proceedings of the Tenth International Cryogenic Engineering Conference," Helsinki, Finland (1984), p. 664 .

10. Q. S. Shu, R.W. Fast and H.L. Hart, Theory and technique for reducing the effect of cracks in multilayer insulation from room temperature to 77K, in: "Advances in Cryogenic Engineering," Vol. 33, Plenum Press, New York (1988), p. 291.

11. Q. S. Shu, R.W. Fast and H.L. Hart, Crack covering patch technique to reduce the heat flux from $77 \mathrm{~K}$ to $4.2 \mathrm{~K}$ through multilayer insulation, in: "Advances in Cryogenic Engineering," Vol. 33, Plenum Press, New York (1988), p. 299. 